\title{
Requirements for the data transfer during the examination of design documentation
}

\author{
Irina Karakozova ${ }^{1}$, and Alexander Pavlov ${ }^{2}$ \\ ${ }^{1}$ Moscow State University of Civil Engineering, 26 Yaroslavskoe sh., Moscow 129337 Russia \\ ${ }^{2}$ All-Russian Research Institute for Operation of Nuclear Power Plant, 25 Ferganskaya str. Moscow \\ 109507 Russia
}

\begin{abstract}
When you transfer the design documents to the examination office, number of incompatible electronic documents increases dramatically. The article discusses the way to solve the problem of transferring of the text and graphic data of design documentation for state and non-state expertise, as well as verification of estimates and requirement management. The methods for the recognition of the system elements and requirements for the transferring of text and graphic design documents are provided. The need to use the classification and coding of various elements of information systems (structures, objects, resources, requirements, contracts, etc.) in data transferring systems is indicated separately. The authors have developed a sequence of document processing and transmission of data during the examination, and propose a language for describing the construction of the facility, taking into account the classification criteria of the structures and construction works.
\end{abstract}

\section{Introduction}

Documentation for the project is the basis for safe and efficient construction, the way to solve problems of investment development. In Russia, as in other countries, the design process is divided into several stages: preliminary design, surveying, permits and approvals, development of design documentation and detailed documentation. In Russia there are state and non-state expertises of project documentation.

This is due to organizational and economic peculiarities of the construction. Design documentation is transferred by using paper and electronic media. Studies showed that design information is analyzed by experts, as a rule, manually.

The objective of the current study was development of methods for transferring of design data from one software system to another, even if they were not jointly developed.

\section{Methods}

\subsection{Methodological features of construction project}

\footnotetext{
* Corresponding author: i.kar@inbox.ru
} 
The main methodology of the study is to analyze the life cycle of construction object [15]. The life cycle of construction object is the period of time during which it exists as an object of management and organization construction, that is, from investment idea to disposal. For most construction projects it takes decades.

In contrast to life cycle, the investment cycle is not management, but the economic notion. It covers part of the life cycle of an object during which it performed the initial investment. Investment cycle can be closed (profits are reinvested in new objects) or open (economical or other result is the ultimate goal of the investment). For the subsequent reconstruction or modernization the new investments require a new study and a separate decision. It is possible to allocate following basic stages of the life cycle of building object (Fig. 1).

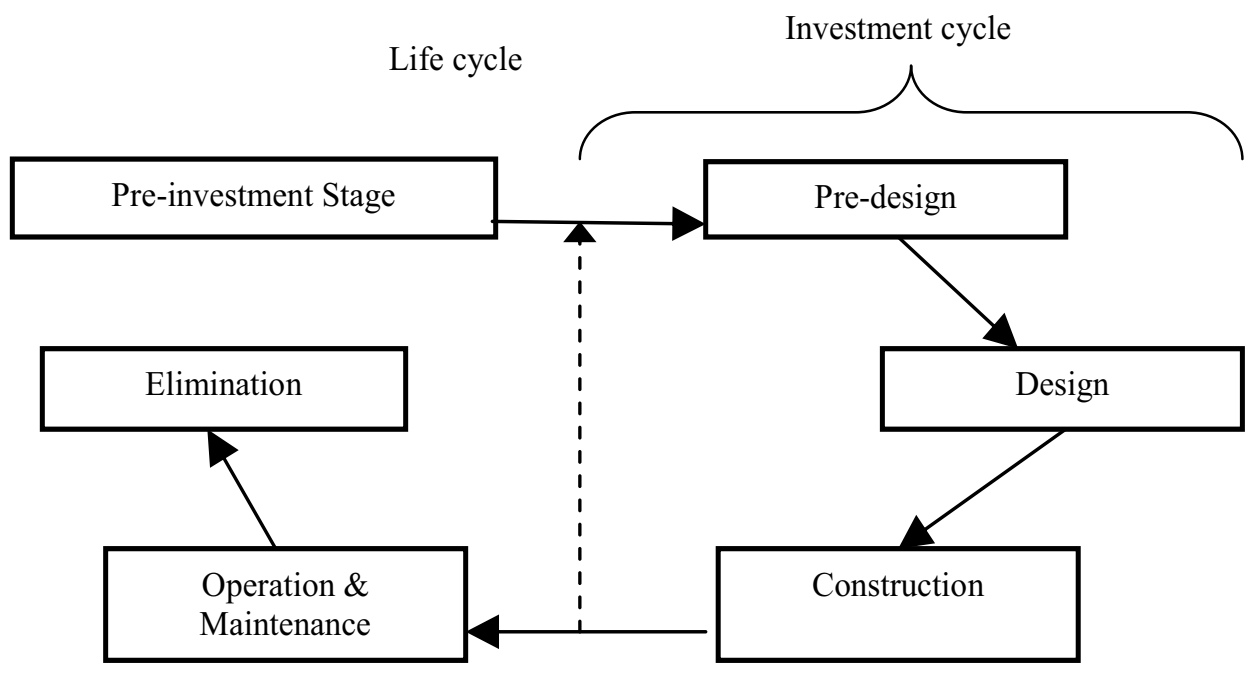

Fig. 1. Life and investment cycles of building object

The pre-investment stage of the project includes actions by state and municipal authorities for territorial planning and preparation of territory for construction. Those are development of schemes of territorial planning, general layouts, rules of land use and development projects of territory planning, etc. For branches which are of national importance, that is development of industry layouts and enterprises: for power generation, transport, extractive industries, etc. These works do not refer to specific objects, and therefore they cannot be attributed to the value of constructed facilities, and, consequently, are not investments. The exceptions are budget investment projects and programs that can enable these actions as the budget investment. This stage will also include the appraisal report.

The content of the pre-design phase is highly dependent on the project particular. It can include the development of a business plan and feasibility study, petition of intent, purchase and registration of land rights, preliminary design, obtaining of technical conditions for connection to networks of engineering support, approval of the design assignment.

The design includes stages of development of design documentation and detailed documentation. At this stage are also carried out engineering surveys, examination and development of tender documents. Detailed design can be combined with the construction phase. The construction phase can be divided into off-site and on-site preparatory period and the main period of construction. For industrial objects construction is divided through the period for construction works, for equipment erection and for commissioning works. The phase ends with the handing over in exploitation. 
The operation phase is the longest phase in the life cycle of the object; they can be last for decades. It consists of periods of useful life (for residential it is accommodation), which are interspersed with periods of repair, modernization and reconstruction. In the beginning can be the stage of the initial operation, which for the industrial objects includes the completion of commissioning, the development of operation processes and formation of sales system. For residential buildings during this period is an individual decoration of apartments, settling and forming of the system of housing and communal services.

The phase of elimination comprises the steps of a production stop (for residential houses - resettlement), demolition and recycling. In the event of termination of the construction is the preservation of the object.

In addition to the life cycle theory, methodology includes the main organizational and methodical features of construction projects. Such features are:

- $\quad$ allocation of a land parcel acquired in the property or taken on a long lease;

- the uniqueness of the object and design documentation;

- $\quad$ impact on the city appearance, urban development, health and safety, environmental and social conditions of people's lives for decades;

- $\quad$ obtaining permits for construction activities in the field of construction, design and surveys;

- $\quad$ large size and complexity of construction objects;

- raising of great financial funds and a large number of logistical, labor and other resources;

- $\quad$ long construction period, phased implementation and acceptance of results of works;

- flexible consideration of individual customer's needs and financial capabilities of consumers;

- determination of rates of construction object and the manifestation of competitive struggle not at the stage of product sales, but during the design, bidding and conclusion of contracts;

- $\quad$ probabilistic assessment of the economic indicators;

- sensitivity in the contracting market to the general economic situation in the country and in the region;

- a great value in the competition reputation of the contractor, experience in construction of similar objects;

- $\quad$ objects move to jobs and jobs move around the object and between objects;

- the participation of many organizations interacting among themselves, usually on a contractual basis; active participation of the owner in construction;

- contractor orientation on a regional market, in combination with the involvement of suppliers in the Russian and international market;

- the same design firm make at the same time a number of objects; the firm need for a uniform load of their units

The third methodological basis of the research was the systems engineering in construction. Systems engineering in construction is a scientific discipline that studies the creation and operation of complex production systems in construction. It brings together the achievements of the learning of life cycle, project management, computer-aided design, information modeling. At the same time, a complex solution of information support of the life cycle does not exist.

\subsection{The development of methods of information support of design}

One of the methods has to improve the quality and efficiency of the design is the introduction of information technology (IT) in the design and construction industry. It is 
known that the use of computer-aided design (CAD) in construction improves the quality and increases the efficiency of designed objects, reduces labor costs and time of design. However, it should be noted that currently the forefront is the problem of reducing the duration of the design, operational changes to the project, monitoring of errors in the documentation. The reduction in the cost of the design and work of designers is not so important, as the cost of design works in the total volume of contract work usually doesn't exceed five percent. In any case, correction of the consequences of design errors is much more expensive than the savings on the project.

In the industrial production automation is an information technology that makes the job through a combination of program management with control feedback. Automated production processes usually involves data logging, elaboration of the optimal technology, management of working bodies, the issuance of messages for the staff. Technical basis of automation is the use of microprocessors, measuring, storage, control and other devices. The feasibility of automation is determined by the effectiveness of its application to increase safety, improve product quality, detecting and correcting in-process errors, improve processes and improve human interaction. We can distinguish between hard, programmable and flexible automation in computer-aided manufacturing (CAM).

A high level of hard automation with a fixed sequence of operations achieved in the sectors of mass production using a continuous production cycle, and production environment in the form of gas, liquid, powder in chemical, petrochemical, food industry, metallurgy. Automation in mechanical engineering started in 1946, when the factories of the Ford Motor Company has been widely applied to automatic control devices, mechanized production lines.

Programmable automation (with change of treatment programs for different batches of products) have found application in the industries with the release of small batches, batch and individual production cycle, such as metalworking, assembly plant. An example of programmable automation is the machines with numerical control, known from 1952. Further development of automation of production has led in 1961 to the emergence of industrial robots, i.e., machines possessing certain anthropomorphic characteristics; in particular, robots include programmable multifunctional manipulators to move parts or tools.

With flexible automation the reprogramming of operations performed without stopping production. Flexible manufacturing system (FMS) typically includes machine tools, conveyor or rotary system processing products and computer system management and control. Human labor applied to the general management and maintenance, loading operations, tool changes and repairs.

Approximately since 1970 in the industry of several countries is used computerintegrated manufacturing - CIM. This is association of automated subsystems of design, production and organizational-economic providing with the direct use of computers. While CIM includes such organizational-economic functions, such as placing orders, counting of spent time, the cost of goods, invoicing, and payroll. The use of CIM increases flexibility of production and increases productivity thanks to optimum capacity utilization.

It should be noted that in the construction, the use of modern information technologies is only the beginning. The most effective result brings the unification of computer aided design and computer aided manufacturing (CAD/CAM, CAD/CAM/CAE). Such systems use the design data directly to generate instructions to machines or robots. In the construction taking into account the specifics of production work, such systems have not yet found application.

However, information technologies are widely used in the design. Computer-aided design (CAD) use of the ability of computers to create and modify a design. Using CAD, the designer creates on the media model of the designed object. The term "CAD" in 
practice usually used for systems that support graphic design. Calculations, analysis and optimization of structures is performed using computer-aided engineering - CAE.

It is possible to allocate in separate groups of IT the product data management (PDM), facility management (FM), geographical information system (GIS), etc. PDM systems provide the interaction between training systems and production management, logistics, marketing, operation and maintenance of equipment. These systems can work in conjunction with other IT. That leads, for example, to the emergence of technological lines according to the scheme "CAD-CAM-CAE-PDM".

As we can see, there is a clear trend towards complex integration of automated systems in a continuous processing line that support the entire product lifecycle - from design to production, operation and even liquidation. With the ability to verify the signature in an electronic document the opportunity to have a paperless technology - the so-called CALStechnologies (Continuous Acquisition and Life Cycle Support) also appears. Therefore the integration of IT is today the most progressive method of manufacturing automation and design.

Modern IT finds wide application in engineering, mainly as CAD. CAD in construction is an interactive organization-technical system, performing design documentation for the construction objects with the use of computers.

The first prototypes of CAD as a computer system with graphical output and is designed to create projects, was established in the early 1960-ies. Ivan Sutherland (MIT) in 1960 used computers by creating the project SKETCHPAD. Professor Charlie Eastman (Carnegie-Mellon) first used a library of blocks for buildings decomposition. In 1962, the company SLS Environetics (Chicago) has developed a computer that does the drawing office interiors.

Around since 1968, software products that we can really call CAD began to appear. Along with the improvement of technical providing CAD (computers, monitors, digitizers, etc.) there are systems designed to automate the creation of technical drawings, primarily in aircraft and automotive industry, for example, CADAM (Computer-Augmented Drafting and Manufacturing). They used mostly two-dimensional graphics models, and pen plotters. In 1973 were introduced the first CAD system in Germany.

In the 1980-ies appear three-dimensional CAD, for example, existing still system CATIA (Computer-Aided Three-Dimensional Interactive Application), MicroStation. There is a parallel distribution of CAD across a variety of hardware platforms.

The 1990s was characterized by widespread workstations and personal computers and graphical window interface. The verbal dialogue changed to a more rapid pictographic dialogue.

One of the most important steps for CAD software is the emergence of powerful systems, solid modeling, for example, Parasolid and ACIS. In more and more systems are equipped with elements of rendering (high quality images with lighting), animations, and photorealistic rendering as well as high quality printing. Network and client-server versions of CAD are extended.

Currently, the basis of collaboration and development are a local area network (LAN), global network Internet, cloud computing. Designers can communicate with each other via e-mail, pages, kiosks and portals online, video and virtual conferencing, on-line access to information, etc.

Analysis of the composition of the software packages shows that the highest demand in the market are complex solutions to ensure full transfer of information from one program to another for the processing chain. This provides a significant reduction of terms of design and high quality of production.

However, in conditions of market competition, the appropriate use of software successfully solves a specific local problem. This is often the total efficiency of CAD 
increases if products are made by various companies-developers, specializing in certain types of IT. In addition, it is possible to use the software, purchased at different times and installed on multiple hardware platforms. For such cases, the acute problem of transmission and transformation of information. When transmitting data on the construction site in automated systems for various purposes (e.g., organizational-economic system or system of buildings) necessary to ensure identification of objects, the completeness of data conversion, validation and conversion, addition of missing data, etc. The task of full transmission of information is one of the most important for the development of modern IT.

Software development in Russia was devoted to solving computational problems of structural mechanics, thermal physics using numerical methods. Late in the $1980 \mathrm{~s}$, we began the development of its own software products in the field of CAD. Therefore, mathematical support of domestic systems was usually ahead of the developments in the field of graphic input and output, dialogue, and geometric modeling.

Close attention is being paid to introduction of information technologies in the process of examination of design documentation and results of engineering surveys. The main issues to be verified during the examination are the compliance of design decisions to results of feasibility study, to mission of design, to input data, and to adopted technical specifications. Also the existence of agreements of the project, the validity of the site choice, the validity the capacity of the facility, the validity and reliability of building solutions based on engineering-geological conditions of construction, the reliability of determination of estimated cost of construction etc. have to be verified.

\section{Results}

CAD-systems created for different types of activity (including structural design) incorporate organizational, technical, informational, mathematical, and in some cases, methodological, metrological, legal and linguistic support. In some cases, the practical development of certain types of support (e.g. technical) is ahead of research and development, and some achievements are quickly becoming obsolete. So, at one time much effort was spent on optimizing the algorithms and programs from the standpoint of economical use of memory and reducing the computation time. In connection with sharp growth of computer specifications, these studies largely lost relevance.

Complex and responsible steps are to develop all types of CAD-software. However, for specific applications, in particular for construction, should be considered essential information, software and linguistic support, as well as methods of transferring information from one information system to another.

These tasks are interrelated and require an integrated system approach. Currently, the most difficult problems in the development of CAD are the formalization of the design process, the software reliability and compatibility of the transmitted data. You can transfer data from one information system to another, which originally had nothing to do with each other. For example, information may be communicated from the architectural application to computational program, from computational program to design system, from design system to the estimating application, etc. When you transfer the documents to the examination office, number of incompatible electronic documents increases dramatically.

The validity and reliability of the construction decisions must be confirmed by the characteristic of space-planning and constructive solutions, by individual design solutions for foundations, by solutions to ensure the strength and stability of buildings and structures and optimization when choosing constructive solutions for thermal protection of enclosing structures of the object.

The sequence of examination individual design approach for foundations is shown in Fig.2. 
The sequence of the examination shown in Fig.2 presupposes the existence of a database where there are a sufficient number of different classifiers, which are grouped information about the object that identifies it according to different characteristics, properties, parameters, etc., inherent only to him.

A special place when calculating future costs is given to the verification process justification of the estimated cost as a single structural element or work package and the project as a whole. In Fig. 2 this stage involves using the results of monitoring that allows to identify the most optimal and reasonable current prices of resources for proposed design solutions. The proposed classifiers of material resources in addition to technical parameters (power, voltage, etc.) can contain other parameters, which include performance and aesthetic properties (color, texture surface, reliability, durability, etc.), hygienic properties (toxicity, resistance to radiation, to biological attack of harmful chemical contaminants etc.) and many others, including, for example, information about the resource price, the name and location of the resource provider.

Thus, the inclusion of an information about constructive solution into the project, all the underlying parameters are automatically placed in a common information system, which allows creating the database and to determine various parameters at each stage in order to detect the deviations of the proposed solutions. In addition, such a database would allow you to use information on cost indexes of various objects of design decisions and work packages, to determine the reliability values costs of construction (capital repair, reconstruction) of capital construction objects based on the results of monitoring the current pricing of resources.

\section{Discussion}

To transfer data from one system to another it is necessary to unify not only the geometric data on the size and shape, but also data on building materials and structures, their properties, types, brands, composition etc. Existing classifications [6, 7] are too small for encoding and transmission of such data array. 


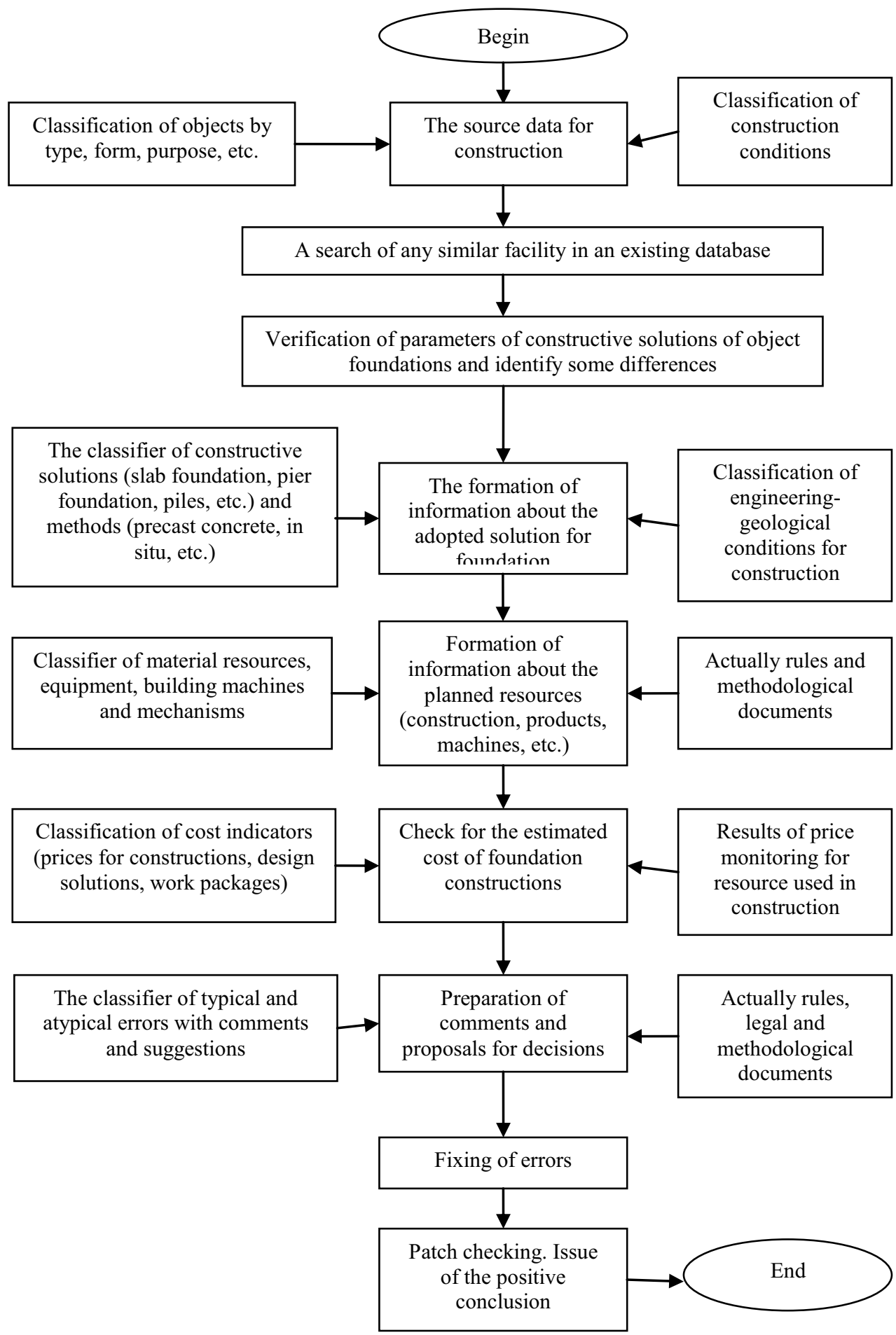

Fig. 2. The sequence of the examination of constructive solutions

The authors propose a language for describing the construction of the facility, taking into account the classification criteria of the structures and construction works $[8,9]$. The power 
of such language shall not be less than the power of the source formats of the participating systems. It is only requires to creating transition modules of software applications for delivery of information in a required data format.

\section{Conclusions}

The main objectives of systems engineering in the field of information management of the construction are the interface between different computer applications, development of effective methods of interaction between customers, contractors, engineers when preparing the production and organization of construction. In particular, the development of a unified system of classification and coding of objects, structures, works and resources of the construction allows the use of information technologies and models (BIM), ensures their comparability.

\section{References}

1. D. Miller, P. H. Friesen. Management Science. 30, 10, 1161-1183 (1984).

2. S. H. Hanks, C. J. Watson, E. Jansen, G. N. Chandler. Entrepreneurship Theory and Practice, 18, Winter, 5-24 (1994)

3. D. L. Lester, J. A. Parnell, A. Carraher. International Journal of Organizational Analysis. 11, 4, 339-354 (2003)

4. S. Kotaji, A. Schuurmans, S. Edwards. Life-cycle assessment in building and construction: A State-of-the-art Report: Society of Environmental Toxicology and Chemistry Press, Pensacola, FL, 19. 3-20 (2003)

5. Systems and software engineering - System life cycle processes. ISO/IEC/IEEE 15288:2015, (IEC, Geneva, 2015).

6. MasterFormat ${ }^{\circledR}$ Number \& Titles (CSI, Alexandria VA, 2016)

7. OmniClass ${ }^{\mathrm{TM}}$ : A Strategy for Classifying the Built Environment, (OCCS Development Committee Secretariat. 2006)

8. I. V. Karakozova, A. S. Pavlov. International Journal of Applied Engineering Research, 10, 23, 43450-43455. (2015)

9. A. Pavlov. Proceedings 16th International Conference on the Applications of Computer Science and Mathematics in Architecture and Civil Engineering, (BauhausUniversität, Weimar, 2003) 